\title{
Research on Ideological and Political Education in Colleges and Universities Based on Mobile Network Learning and Its Guidance
}

\author{
Wang Xiaomei \\ College of Sciences and Humanities of Northeast Normal University, Changchun, Jilin Province 130117, \\ China \\ wangxiaomeijl@126.com
}

Keywords: mobile network learning; campus network; network course

\begin{abstract}
Today's society is transforming into a mobile network society, which is the trend of social development. When this social trend gradually becomes a habit in people's lives, since entering the 21st century, mobile network learning is such a typical social trend. In this century, science and technology are constantly advancing and developing. With the continuous improvement of information technology and network technology, more and more people are integrated into education. The network has gradually become a powerful resource for students to learn independently, as well as an important means and method for both teaching and learning. Network has become an indispensable means of learning for students. Knowledge is far more important than power as a strategic resource. Today's Internet is built on the basis of knowledge, centered on a variety of core knowledge, and the most important knowledge of science, technology and finance today. Compared with the social core of a hundred years ago, the social structure has undergone tremendous changes, which has brought about the transformation of educational resources and learning methods. Mobility, however, has become an increasingly prominent feature of the world. Hand held mobile devices, such as digital mobile phones, PDAs, iPads, tablets, and so on, are available for us to access, process and send messages everywhere, and perform communication everywhere, share information everywhere, and taking advantage of this opportunity, mobile intelligent terminal devices and wireless network are relied on to carry out educational activities, transfer the value of knowledge, and realize human learning in infinite space, As the carrier of presenting learning resources, human-computer interaction and social cognition construction, mobile learning plays a fundamental and supporting role in today's learning. The role of mobile learning, the location and function of learning directly affect the paradigm and effect.
\end{abstract}

\section{Mobile Network Education}

Mobile network education refers to the education implemented through the network in a mobile learning place or using mobile learning tools. Compared with the education implemented in a fixed learning place (which can be called fixed education), Mobile network education is characterized by mobility, flexibility and convenience. Throughout the history of human education, in fact, it is also a mutual promotion between mobile education and fixed education. The history of human mobile education can be divided into five generations: the first generation of mobile education refers to the education carried out through the teaching of words and deeds in the primitive labor. The second generation of mobile education refers to the use of printed books and correspondence courses. The third generation of mobile education refers to the use of wireless broadcasting and "Walkman" education. The fourth generation of mobile education refers to the use of television and video DVDVCD and the implementation of the education. Education refers to the use of wireless networks and mobile information tools, such as mobile phones, Palmtop Computer, electronic schoolbag, etc. At present, "mobile education" is usually referred to as "mobile education". In the future, mobile learning tools will have higher intelligence and more integration, and mobile education will be more convenient, diverse and efficient. 


\section{The Influence of Mobile Network Science on Ideological and Political Education in Colleges and Universities}

With the openness and convenience of the mobile Internet, many college students can quickly find all kinds of open or internal, real or false information through the mobile phone they carry with them, so that they can no longer easily accept the blindly instilled by traditional ideological and political educators in colleges and universities. If the content taught by a teacher is not sufficiently persuasive or sensitive to new things, students will have doubts about what the teacher teaches, thereby affecting the authority of the teacher. They are more willing to learn on their own. However, due to the lack of sensitivity to accepting new things and various pressures such as work and life, educators are slow to accept the mobile Internet under limited energy and cannot adapt to the changes in the educational environment in time. Often in the situation of information inferiority, and there are weak awareness of technology, technical level is poor and other deficiencies. The openness of the mobile Internet makes it easier and easier for college students to understand the cultural traditions, ideas, religious beliefs, and lifestyles of different countries. This inevitably affects the already immature values and outlook on life of college students. In particular, the information pollution created by Western countries in the process of cultural colonization with deliberate and ulterior motives will further impact the values and outlook on life of college students. In addition, in the process of commercialization of the mobile Internet, in the business atmosphere of profit seeking, All kinds of online virtual games full of violence, pornography, superstition, inciting hype, refocusing on headlines, psychological cues, etc., can be caused by the existence of the value chain Stop the appearance and renewal, how can not affect the values and outlook on life of college students. From a technical point of view, the mobile Internet is the combination of mobile communication devices and the Internet. It has greater freedom of information dissemination and more sources. It may come from mobile phone users or from the traditional Internet. It is more likely to come from information suppliers. Technically, it will be much more difficult to regulate mobile Internet information than the traditional Internet with IP address terminals. At present, when the regulatory technology is not mature, the country, the society has weak supervision over the mobile internet, a new type of network media. Moreover, in the mobile internet environment, the real society and the network society are more closely linked, more exchanges, more problems, the network management Therefore, the uncontrollable of network security and its openness will inevitably increase the complexity of ideological and political education work environment. With the use of the mobile Internet, teachers can view and collect multimedia resources related to ideological and political education, such as sound, video and video, anytime and anywhere through the network, making ideological and political education from plane to three-dimensional. From static to dynamic, so as to enhance the interaction, interest and appeal of college students' ideological and political education. College students can also search for what they need through the mobile network, not only can they not be limited by time and place, you can also browse online and download expert lectures and lectures in the field of ideology and politics quickly. The traditional contents of ideological and political education are mostly confined to the cultivation of students' political literacy and ideological character. Therefore, most of the educational contents are characterized by high stylistic orientation, general and lack of pertinence, which leads to the lack of new ideas and appeal of ideological and political education. Students are not interested. In view of this situation, ideological and political educators should make full use of multimedia resources such as sound, video and video of the mobile Internet, and aim at the hot and focused issues of concern to college students, from ideological, political, moral, legal and disciplinary issues. This paper analyzes the psychological aspects and combines the contents of college students' study, employment, making friends, psychological counseling, legal aid, and so on, to dig deeply into the ideas in the study, employment, making friends, psychological counseling, and legal aid and so on. The connotation of political education attracts the interest of college students and provides service for them. The mobile characteristics of the mobile Internet, so that university education no longer have to be limited by a fixed limited space and time, such as a specific time, a specific classroom, as long as there is a mobile phone signal, mobile teaching can be achieved at any time, instant 
communication, interaction, convenience, The virtual nature of mobile teaching can avoid the embarrassment of face-to-face communication. Students can speak freely and anonymously. The openness of the mobile Internet is also a solution for schools. Society and family, forming the resultant force of education, offer the possibility. These put forward the positive challenge to the traditional position and the traditional way of ideological and political education .In order to create a positive and positive network public opinion environment on campus, colleges and universities should strengthen the supervision and management of campus websites. Propagate some positive and positive ideas and give correct guidance to the students. First of all, emphasize the orientation in the content. Fix the content of the website within the appropriate scope, mainly to solve the students' practical problems. At the same time, ideological and political teachers can organize students to concentrate on learning typical cases related to them, through case analysis and explanation to help students realize the dangers of distorted values and promote the mainstream of health thinking in the Internet. Use the Internet as an effective platform. It has effectively promoted the smooth progress of ideological and political education in colleges and universities. Secondly, it presents diversity in form. At the same time, to correct some radical and wrong comments on the campus website, strengthen the management of network comments, and create a healthy and positive network environment for students.

Principles of instructional Design for Mobile Learning

Mobile learning is different from traditional classroom teaching and fixed distance education. Mobile learning mainly meets the learning needs of students in scattered time. Students can use mobile learning system to accept their favorite learning content at anytime and anywhere. Teachers can also solve the problems encountered by students in learning conveniently and timely. Due to these characteristics, the following principles should be followed in the design of mobile learning teaching:

Embody open thinking; teaching objectives should be quantified. Mobile learning mainly uses mobile tools to learn knowledge, which requires instructional designers to design the teaching objectives of each teaching unit clearly. Instead of just using words such as knowledge, understanding, synthesis, and so on, we should quantify the teaching objectives with certain exercises, quizzes, or other methods so that students can clearly understand what they have learned after learning this unit. Teaching units should be short. The biggest advantage of mobile learning is to meet the needs of students at anytime and anywhere. Students may have to do housework or other social activities in their spare time, so they don't have a large amount of time to study. Mobile learning has no strict requirements for the learning environment and can be carried out anywhere. However, if the external interference factors increase, learning may be interrupted at any time. Therefore, mobile learning teaching units should be short, preferably between 10-30 minutes. This allows learners to master a knowledge point in a short period of time and increase their chances of learning a unit without interference. Good packaging of teaching unit. The teaching unit is good in encapsulation, and cannot be particularly close to the front - to - back connection. When the learner finishes the unit, it can be put on hold, and the next unit can be learned after learning the unit. If the encapsulation is not good, the student is interfered with many times when learning the unit. Then he can only step in, and the next time he studies, he will continue to learn the unit and waste a lot of time.

\section{Conclusion}

Mobile learning is developing rapidly. Mobile learning is developed on the basis of digital learning and is an extension of digital learning, which is different from general learning. Since the development in China in 2003, more and more attention has been paid to the research by educational technology experts and scholars, and the related research papers have also been increasing and the overall trend is on the rise. From 2010 to 2011, the number of papers declined slightly in 2012, and the slight increase in 2013 shows that the attention to mobile learning is unstable. Some experts believe that the research has been paid much attention and attention, so the line of sight is shifted to other aspects, but there are still many problems that need us to study and 
explore .At the same time, in recent years, mobile learning has also shown an explosive trend in domestic development, so now mobile learning needs more sustained and stable attention from all of us, so that it can be developed more fully and comprehensively. The occurrence of mobile learning is more and more dependent on the digital environment, which can also be regarded as the application environment of mobile learning. Generally speaking, the mobile learning environment is composed of four parts: mobile learning network access technology, mobile learning platform and system, mobile learning resources and mobile learning terminal equipment. In the framework of mobile learning application environment, the most important is the infrastructure of network access, and the mobile learning platform is a software system running on the server side to support learning content and activities. Mobile learning resources refer to all kinds of information resources that support mobile learning, including learning materials, to help learners to obtain, process, preserve information, learning space and so on; mobile learning terminal equipment through the network learning platform to obtain learning resources, And with the learning environment to achieve interaction. Therefore, the study of mobile learning environment should be more adequate to promote people's learning and development.

Mobile learning is convenient and fast, it has been recognized by a large mobile terminal user group, and users actively search, download the use of learning applications, especially in primary and secondary schools and college students. However, in the whole learning behavior of learners, mobile learning has not yet formed the mainstream of learning style. The main reason is that the awareness of mobile learning is still in its infancy, and the user has a process of cultivation. In part, book-based and face-to-face learning is still the mainstream, especially book-based learning, which will remain dominant in the next decade but this does not mean that mobile learning does not do anything, which just shows that mobile learning is a very good "marginal application". In combination with books and face-to-face training, mobile learning has a natural advantage. Therefore, journals should pay more attention to mobile learning, research and publication, so as to make the concept of mobile learning more popular, improve the efficiency and quality of learning.

With the continuous development of network technology, mobile network learning based on this will permeate all aspects of society, and colleges and universities are no exception. Mobile network learning has created a rare opportunity for ideological and political education in colleges and universities. Under the environment of mobile network learning, ideological and political education in colleges and universities has gained more space for development, whether it is permeability, influence, or attraction. At the same time, Ideological and political education in colleges and universities is also facing a severe test, such as the traditional mode of ideological and political education in colleges and universities has been increasingly unable to keep pace with the pace of the times, the transformation of ideas and model innovation has been forced In view of this, this paper makes a positive discussion on the guiding measures of ideological and political education in colleges and universities under the mobile network learning, and puts forward some relevant suggestions, including the establishment of a positive and upward campus website, and the establishment of a monitoring and early warning mechanism. In order to provide some useful reference for the development of the related work in universities and colleges, it is necessary to forge a professional network political work team and to deal with the sudden crisis.

\section{References}

[1] H. L.L, Mobile Network Learning, China University of Science and Technology Press, 2011.

[2] W. W.L, Mobile Communication, Electronic Industry Press, 2009.

[3] Z. J.W, Mobile Communications (fourth Edition), Xi'an University of Electronic Science and Technology Press, 2013.

[4] H. R.H; S. J.R, Introduction to educational technology, Higher education press, 2006.

[5] S. X.M, Learning science and technology, Higher education press, 2004. 
[6] L.J.X, GSM Digital Mobile Communication Foundation, Electronics Industry Press, 1995.

[7] S. M etc., DSP principle and its Application in Mobile Communication, people's Post and Telecommunications Publishing House, 2001.

[8] Schwartz, Mobile wireless communications, electronic industry press, 2006.

[9] Chris. Anderson, the Long Tail, Chris Anderson, 2006. 